\title{
Recent Advances Towards the Development of a Potent Antiviral Against the Hepatitis E Virus
}

\author{
Saumya Anang, Nidhi Kaushik and Milan Surjit* \\ Virology Laboratory, Vaccine and Infectious Disease Research Centre, Translational Health Science and \\ Technology Institute, NCR Biotech Science Cluster, 3rd Milestone, Faridabad-Gurgaon Expressway,
} Faridabad, Haryana, India

\begin{abstract}
Hepatitis E virus (HEV) is one of the leading causes of acute viral hepatitis. It also causes acute liver failure and acute-onchronic liver failure in many patients, such as those suffering from other infections/ liver injuries or organ transplant/chemotherapy recipients. Despite widespread sporadic and epidemic incidents, there is no specific treatment against HEV, justifying an urgent need for developing a potent antiviral against it. This review summarizes the known antiviral candidates and provides an overview of the potential targets for the development of specific antivirals against HEV.

Citation of this article: Anang $S$, Kaushik N, Surjit M. Recent advances towards the development of a potent antiviral against the hepatitis E virus. J Clin Transl Hepatol 2018; 6(3):310-316. doi: 10.14218/JCTH.2018.00005.
\end{abstract}

\section{Introduction}

Hepatitis E virus (HEV) is a positive-sense, single-strand RNA virus that causes acute and chronic viral hepatitis, fulminant hepatitis, acute liver failure and acute-on-chronic liver failure in infected individuals. ${ }^{1}$ It is known to be transmitted through the fecal-oral route, transfusion of infected blood products or through the vertical route. ${ }^{2-7}$ Zoonotic transmission due to consumption of infected meat products, resulting in sporadic cases, is particularly frequent in developed countries. ${ }^{8}$ The disease symptoms include jaundice, nausea, vomiting, fever and sore muscles. Though the infection is acute in normal individuals, it becomes chronic in immunocompromised patients, such as organ transplant recipients, individuals infected with the human immunodeficiency virus, and patients undergoing chemotherapy. ${ }^{9-14}$ The disease worsens in pregnancy, with mortality rates reaching as high as 20 to $25 \% .^{6,15,16}$ Recent reports have described extra-hepatic manifestations, such as GuillainBarre syndrome, neurological amyotrophy, arthritis, pancreatitis and glomerulonephritis, in several HEV infected patients. ${ }^{17-19}$

Keywords: Hepatitis E virus; HEV antiviral; HEV therapy; Interferon; Ribavirin Abbreviations: 66E2, 1-(9-ethylcarbazol-3-yl)-3-(2-methyl-4-nitrophenyl) urea; Grp78, glucose-regulated protein 78; HCV, hepatitis C virus; HEV, hepatitis E virus; MG132, carbobenzyl-Leu-Leu-Leu-aldehyde; PEG-IFN- $\alpha$, pegylatedinterferon-alpha; PPMO, peptide-conjugated morpholino oligomer

Received: 16 January 2018; Revised: 19 February 2018; Accepted: 23 March 2018

*Correspondence to: Milan Surjit, Vaccine and Infectious Disease Research Centre, Translational Health Science and Technology Institute, NCR Biotech Science Cluster, 3rd Milestone, Faridabad-Gurgaon Expressway, PO Box No. 04, Faridabad-121001, Haryana, India. Tel: +91-129-2876-318, Fax: +91-1292876400, E-mail: milan@thsti.res.in
Drave et al. ${ }^{20}$ have also demonstrated the replication of HEV in human neuronal-derived cell lines.

Out of the eight recognized genotypes of HEV, genotypes 1 and 2 were responsible for about 20.1 million infections in 2005 including 3.4 million symptomatic cases, 70,000 fatalities and 30,000 still births. ${ }^{21}$ Outbreaks of HEV have been reported from different parts of the world. Several parts of eastern and the central India, including Orissa, Chhattisgarh, Maharashtra and Nellore, witnessed HEV outbreaks between 2008-2017. ${ }^{22-25}$ Many parts of Africa have also been affected by frequent HEV epidemics. Outbreaks were also reported from Egypt, Uganda, Sudan, Ethiopia, Chad, Niger and Kenya. ${ }^{26}$ An outbreak has even been reported from Australia, caused by a locally-acquired $\mathrm{HEV}^{27}$ The recent increase in organ transplantation and exposure to the disease due to growing trade and travel has further expanded the incidence of HEV infection, thereby intensifying the need for research of antivirals against HEV.

Currently available treatments against HEV and their limitations

HEV-induced acute hepatitis is usually self-limiting. The disease is generally cured in 4-6 weeks, without the need of any medication. During severe acute and chronic infections, a reduction in immunosuppressant dose or administration of pegylated-interferon-alpha (PEG-IFN- $\alpha$ ), ribavirin or a combination of both is the available therapeutic option. Reduction in immunosuppressant dose helps in virus clearance in approximately $30 \%$ of organ transplant patients. ${ }^{28}$

Ribavirin monotherapy has been found to be effective in the treatment of chronic HEV infection. ${ }^{29-32}$ Ribavirin inhibits host inosine monophosphate dehydrogenase, thereby depleting cellular GTP pools and blocking viral replication during HEV infection. ${ }^{33}$ Another possible mechanism of ribavirin action on HEV is attributed to its ability to induce mutations in the viral genome (Fig. 1). The G1634R mutation in the HEV polymerase increases the replication competence of the HEV genome and has been shown to confer resistance against ribavirin treatment in some patients. However, subsequent studies revealed that the G1634R mutation does not lead to absolute ribavirin resistance. ${ }^{34-37}$

A major limitation of ribavirin therapy is attributed to the undesirable consequences of the treatment, such as: (i) it's not being a treatment option during pregnancy, owing to its teratogenicity; (ii) its potential to cause hemolytic anemia and decreased hemoglobin, requiring direct supervision of hemolytic parameters during its application; ${ }^{38}$ and (iii) its potential to cause insomnia, dyspnea, lack of concentration and irritability. ${ }^{38}$ 
Anang S. et al: Antiviral against the hepatitis E virus

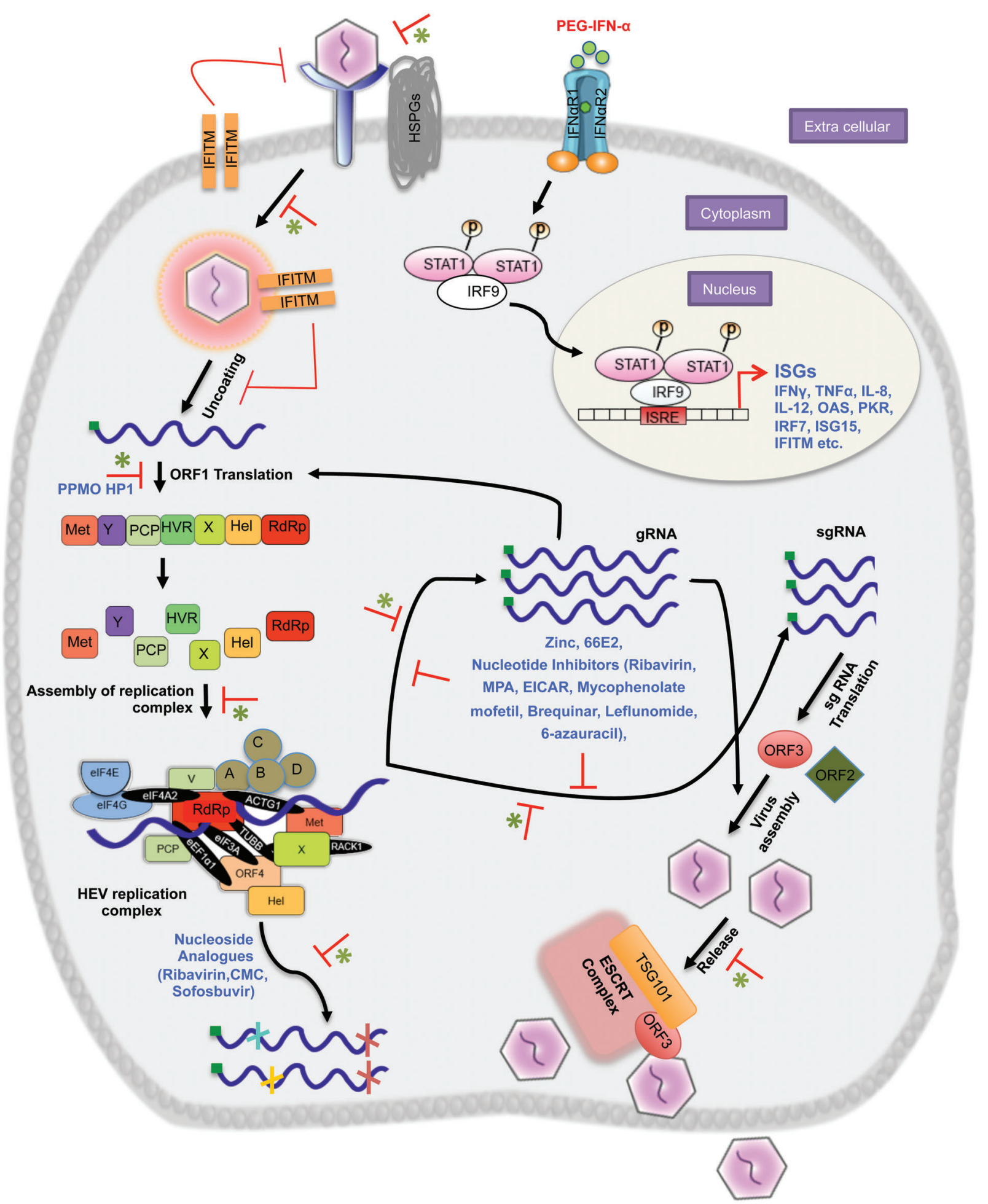

Fig. 1. Summary of HEV life cycle and the target sites of approved and potential antivirals. HEV enters a permissive cell supposedly through a receptor-dependent process, aided by heparan sulfate proteoglycans (HSPGs) and other unknown factors. The viral genome is released, ORF1 gets translated and processed into different functional domains, followed by replication. Multiple copies of capped ( green box) genomic (g)RNA and subgenomic (sg)RNAs are thus produced. SgRNAs synthesize viral capsid (ORF2) and ORF3 proteins. ORF2, gRNA and other viral and/or host factors mediate assembly of new virions, which are released out of the cell through an endosomal sorting complex required for transport (ESCRT)-dependent process involving the viral ORF3 protein. The green asterik indicates the steps that can be targeted for antiviral development. A, B, C and D represent the unknown factors present in the viral replication complex. Note that ORF4 is present only in the case of genotype $1 \mathrm{HEV}$. Known antivirals have been indicated at the appropriate steps. The mode of pegylated-interferon-alpha (PEG-IFN- $\alpha$ ) action is represented through the illustration of the inteferonalpha (IFN- $\alpha$ ) signaling pathway. PEG-IFN- $\alpha$ induces the production of interferon-stimulated proteins (ISGs) and interferon-inducible transmemebrane proteins (IFITM), which activate the canonical antiviral signaling pathways that results in the inhibition of HEV entry and/or replication. 
Also of note is the fact that although ribavirin treatment for chronic HEV-infected organ transplantation recipients is effective in the majority of cases, it does not reach a $100 \%$ success rate. ${ }^{34}$ Further, in a study involving a chronic HEV-infected Burkitt's lymphoma patient treated with chemotherapy, 8 months of ribavirin treatment failed to eliminate the HEV. ${ }^{14}$

PEG-IFN- $\alpha$ has been used in patients with liver transplant, kidney transplant, human immunodeficiency virus infection and leukemia who are chronically infected with HEV. ${ }^{39-42}$ The mechanism by which PEG-IFN- $\alpha$ clears HEV is not clearly understood. However, all the types of IFN, including IFN- $\alpha$ (type I), IFN- $\gamma$ (type II), and IFN- $\lambda 3$ (type III) inhibit HEV replication and IFN- $\alpha$ subtypes $2 a$ and $2 b$ exert the strongest antiviral activity against HEV in mammalian cell culture. ${ }^{43}$ $\mathrm{HEV}$ is also equipped with multiple strategies to restrict the IFN response, leading to moderate and delayed anti-HEV effects in vitro and in patients treated with IFN- $\alpha .{ }^{44}$

The HEV $X$ and papain-like cysteine protease domains inhibit IFN (type I) induction, while HEV ORF3 is known to inhibit IFN- $\alpha$ signaling by inhibiting phosphorylation of STAT $1.45,46$ Interestingly, ORF3 also inhibits phosphorylation and nuclear translocation of STAT3 as well as expression of its target genes in cells treated with epidermal growth factor. ${ }^{47}$ Further studies using suitable in vivo models should decipher the significance of the crosstalk between host interferon signaling and the viral interferon restriction factors.

The common side effect associated with IFN treatment is flu-like symptoms. Among the more serious adverse effects are neuropsychiatric disorders, neurologic disturbances, myelosuppression, cardiovascular disorders, altered liver function, renal insufficiency and gastrointestinal manifestations. ${ }^{48}$ Further, 3 months of treatment with PEG-IFN- $\alpha-2 a$ is reported to result in sustained virolgical response in 2 out of 3 chronic HEV-infected liver transplant patients. ${ }^{49}$

In summary, PEG-IFN- $\alpha$ treatment appears to be a promising therapeutic option against HEV infection. Nevertheless, additional studies involving large cohorts of patients should provide a better understanding of its therapeutic benefits.

\section{Perspectives towards development of potent antivirals against HEV}

Several laboratories have been focusing on identifying suitable drug targets and developing antivirals against HEV. ${ }^{50}$ Summarized below is the outcome of recent efforts to identify potent antivirals against HEV.

\section{Antiviral effect of inhibitors of the nucleotide synthesis pathway}

Inosine monophosphate dehydrogenase is an essential enzyme in the purine biosynthesis pathway. Several inosine monophosphate dehydrogenase inhibitors, such as mycophenolic acid, ribavirin and 5-ethynyl-1- $\beta$-D-ribofuranosylimidazole-4carboxamide, inhibit HEV replication. ${ }^{33,51}$ The combination of mycophenolic acid and ribavirin acts more effectively to inhibit HEV replication than mycophenolic acid or ribavirin alone. ${ }^{51}$ Further, mycophenolate mofetil, a prodrug of mycophenolic acid, exhibited frequent HEV clearance in heart transplant patients, providing protection from chronification. ${ }^{51}$

Dihydroorotate dehydrogenase and orotidine-5'-monophosphate decarboxylase are essential enzymes in the pyrimidine biosynthesis pathway. Dihydroorotate dehydrogenase inhibitors, such as brequinar, leflunomide and orotidine-5'-monophosphate decarboxylase inhibitor 6-azauracil, also inhibit HEV replication in mammalian cell culture models. ${ }^{52}$ These compounds deserve further validation as antivirals against HEV.

\section{Antiviral effect of nucleoside analogues}

2 -C-methylcytidine is a nucleoside analogue that efficiently inhibits HEV replication in the cell culture system. ${ }^{53}$ It was also shown that 2'-C-methylcytidine retained anti-HEV activity even after long-term exposure to the virus, implying its potential use to combat development of drug resistance. ${ }^{53}$ However, 2'-C-methylcytidine showed an antagonistic effect when tested in combination therapy with ribavirin. ${ }^{53}$ Further in vivo evaluation of this compound should provide insights about its antiHEV effects.

Sofosbuvir, a prodrug of a uridine nucleoside analogue that acts as a direct-acting antiviral against hepatitis $C$ virus (HCV) RNA-dependent RNA polymerase in its active form, was reported by Dao Thi et al. ${ }^{54}$ to inhibit HEV genotype 3 replication in vitro and to exert additive effect when combined with ribavirin. However, those data were not fully reproducible by Wang et al. ${ }^{55}$ and, moreover, sofosbuvir treatment failed to clear HEV viremia in an immunosuppressed patient with chronic HCV and HEV without ribavirin. ${ }^{56}$ Therefore, usage of sofosbuvir as an anti-HEV therapeutic needs further validation (discussed further in the RNA-dependent RNA polymerase section of this manuscript).

\section{Antiviral effect of peptide-conjugated morpholino oligomers (PPMOs)}

The Zhang laboratory ${ }^{57}$ developed HEV-specific PPMOs and evaluated their efficacy in inhibiting viral replication. Out of the four PPMOs tested, PPMO HP1 was most effective in reducing viral replication in mammalian cell culture. ${ }^{57}$ PPMO HP1 specifically inhibits viral translation by targeting a highly conserved sequence in the start region of ORF1 of genotype 1 and genotype 3 HEV. Treatment of cells with 2, 4 and $8 \mu$ M of PPMO HP1 reduced luciferase expression by $53.4 \%, 94.4 \%$ and $99.7 \%$, respectively, in a luciferase reporter based HEV replicon system. ${ }^{57}$ The antiviral activity of PPMO HP1 was specific, dose-responsive and potent. Hence, its further validation as a potential HEV-specific antiviral is warranted.

\section{1-(9-ethylcarbazol-3-yI)-3-(2-methyl-4-nitrophenyI) urea (66E2)}

66E2 has been identified as an inhibitor of HEV replication in hepatocytes. ${ }^{58}$ 66E2 inhibits genotype $3 \mathrm{HEV}$ replication by $\sim 50 \%$, without producing any detectable cytotoxicity. Interestingly, 66E2 also inhibits HCV and Dengue virus replication. ${ }^{58}$ The mechanism by which $66 \mathrm{E} 2$ inhibits viral replication remains to be explored.

\section{Carbobenzyl-Leu-Leu-Leu-aldehyde (MG132)}

Mg132 is a cell permeable inhibitor of the host 26S proteasome complex, which is responsible for degradation of ubiquitinated proteins. It also inhibits serine and cysteine proteases with lower efficiency. It is also known to induce c-Jun N-terminal kinase-dependent apoptosis, to inhibit NFKB activity and to block $\beta$-secretase cleavage. ${ }^{59}$ Karpe et al. ${ }^{60}$ reported significant inhibition of HEV replication-related luciferase activity in cells treated with MG132. However, it was subsequently shown that 
MG132 also reduced the cellular RNA and protein levels, indicating its effect to be nonspecific. ${ }^{61}$

\section{Zinc}

A recent report by Kaushik et al. ${ }^{62}$ has demonstrated the antiviral activity of zinc against HEV. Zinc is an essential micronutrient, which plays a crucial role in multiple cellular processes. It also acts as a broad-spectrum antimicrobial against several pathogens. ${ }^{63,64}$ Zinc salts were shown to block the replication of both genotype 1 and genotype $3 \mathrm{HEV}$ by inhibiting the activity of viral RNA-dependent RNA polymerase in cultured human hepatoma cells. ${ }^{62}$ Further, zinc salts did not affect virus entry into the host cell.

Zinc also displayed moderate cooperativity with ribavirin in inhibiting viral replication. These data indicate the possible therapeutic usage of zinc in controlling HEV infection. However, considering the complexities involved in serum/plasma and intracellular zinc homeostasis, ${ }^{65}$ the efficacy of zinc in inhibiting HEV replication in vivo remains to be evaluated. Moreover, the detailed mechanism(s) underlying the inhibitory action of zinc on HEV replication needs to be investigated.

\section{Potential targets for antiviral development against HEV}

The following stages of the HEV life cycle are potential targets for the development of specific antivirals (Fig. 1).

\section{Virus entry into the host cell}

The specific receptor by which HEV enters the host cell is unknown. However, it has been demonstrated that heparin sulfate proteoglycans may serve as attachment receptors to facilitate HEV entry into the host cells. ${ }^{66}$ The HEV capsid protein ORF2 also interacts with heat shock protein 90 and glucoseregulated protein 78 (Grp78). Grp78 or heat shock protein 90 may be involved in the intracellular transport of the virus. ${ }^{67,68}$ Grp78 has also been shown to interact with the envelope protein of the Japanese encephalitis virus, facilitating its entry into the host cells. ${ }^{69}$ It remains to be tested whether Grp78 and ORF2 interaction mediates HEV entry. Inhibitors of receptor binding or intracellular transport of the virus are supposed to block viral life cycle at a very early stage.

\section{Capping of the viral genome}

Among the nonstructural proteins encoded by the HEV ORF1, methyltransferase is responsible for capping of the viral genome. ${ }^{70}$ Addition of a 7-methylguanosine cap at the $5^{\prime}$ terminus of the viral genome confers stability and protects the viral RNA from the host innate immune effectors. ${ }^{71}$ Uncapped HEV RNA is inefficient in replication. ${ }^{72}$ Moreover, in contrast to the host methyltransferases wherein guanyltransferase donates a GMP moiety to the RNA, followed by cap methylation by guanine-7-methyltransferase activity; HEV methyltransferase follows a reverse order, thereby restricting its activity to the viral RNA. ${ }^{70}$ Therefore, inhibition of HEV methyltransferase activity appears to be a potent antiviral strategy. It is noteworthy that Neplanocin A and 3-deaza-adenosine, the two known inhibitors of influenza virus methyltransferases, interfere with virus replication. ${ }^{73}$ Neplanocin A is also a potent inhibitor of vaccinia virus replication. ${ }^{74}$ Inhibitors against Dengue virus methyltransferases have also been screened. ${ }^{75}$

\section{Replication of the viral genome}

Direct-acting inhibitors of HEV RNA-dependent RNA polymerase function: RNA-dependent RNA polymerase is the most important factor in the life cycle of all RNA viruses and, therefore, RNA-dependent RNA polymerase inhibitors are supposed to be potent antivirals. One such antiviral against HCV is sofosbuvir, which acts by inhibiting the activity of HCV RNAdependent RNA polymerase. ${ }^{76}$ Dao Thi et al. indicated the effectiveness of sofosbuvir in inhibiting HEV replication; however, subsequent studies failed to observe its potent inhibitory effect. ${ }^{54-56}$ Nevertheless, optimization of the sofosbuvir structure that improves its inhibitory effect on HEV RNA-dependent RNA polymerase is an attractive area of investigation. Knowledge of HEV RNA-dependent RNA polymerase structure might expedite the above study. Apart from sofosbuvir-like molecules, new chemical entities should be explored to identify potent inhibitors of HEV RNA-dependent RNA polymerase activity.

Other inhibitors of HEV RNA-dependent RNA polymerase function: Our earlier studies showed that the interaction between host eEF1 $\alpha 1$ and viral RNA-dependent RNA polymerase is important for optimal RNA-dependent RNA polymerase activity. ${ }^{77}$ We recently reported the construction and characterization of the host-virus protein-protein interaction network of HEV. ${ }^{78}$ Using a yeast two-hybrid CDNA library screening-based approach, 41 host proteins were identified to be the direct interaction partners of g-1 HEV RNA-dependent RNA polymerase and 23 of them could also associate with g3-HEV RNA-dependent RNA polymerase. Notably, host translation regulatory factors, such as eIF4A2, eEF1 $\alpha 1$ and eIF3A, directly associated with the RNA-dependent RNA polymerase protein of both genotype 1 and genotype $3 \mathrm{HEV}$.

Further in silico analysis of the functional significance of the protein-protein interaction network revealed distinct protein-protein interaction clusters in the secondary network, representing enrichment of proteins involved in different host processes, such as translation initiation, the ubiquitin proteasome pathway and the oxidative phosphorylation pathway. Depletion of the translation regulatory factors by gene silencing technique resulted in significant reduction of viral replication and pull-down studies under similar conditions revealed the assembly of a multiprotein complex consisting of the translation regulatory factors, RNA-dependent RNA polymerase and many other virus and host factors. Remarkably, eEF1 $\alpha 1$ was identified to be the most important host factor for maintaining the integrity of the above multiprotein complex, thereby suggesting it to be an attractive target for antiviral discovery. Additionally, inhibitors against other host translation factors present in the complex such as eIF4A2 and eIF3A are also supposed to block viral replication. Targeting a combination of direct and indirect inhibitors of RNA-dependent RNA polymerase function might prove to be an apt antiviral strategy against HEV.

Inhibitors of helicase function: HEV helicase is a nucleoside triphosphatase with the ability to unwind RNA duplexes in the $5^{\prime}$ to $3^{\prime}$ direction, thus playing a role in HEV replication. ${ }^{79}$ Due to the common properties shared between the helicases encoded by viruses and their host, designing inhibitors against helicases is challenging. Nevertheless, potent inhibitors of helicase encoded by the herpes simplex virus, severe acute respiratory syndrome coronavirus, HCV, dengue virus, Japanese encephalitis virus, West Nile virus and human papillomavirus have been reported. ${ }^{80}$ The new series of thiazolylphenyl-containing herpes simplex virus helicaseprimase inhibitors are active in animal models and offer a new 
Anang S. et al: Antiviral against the hepatitis E virus

Table 1. Summary of the approved and potential antivirals against HEV

\begin{tabular}{|c|c|c|c|}
\hline Name & Target stage & Mode of action & References \\
\hline \multicolumn{4}{|l|}{ Approved drug } \\
\hline Ribavirin & HEV replication inhibitor & $\begin{array}{l}\text { Inhibits inosine monophosphate } \\
\text { dehydrogenase, guanosine } \\
\text { analogue }\end{array}$ & $33-37$ \\
\hline Pegylated-interferon- $\alpha$ & HEV replication inhibitor & Interferon- $\alpha$ receptor agonist & 43 \\
\hline \multicolumn{4}{|l|}{ Potential candidate } \\
\hline $\begin{array}{l}\text { Mycophenolic acid, 5-ethynyl-1- } \beta-D- \\
\text { ribofuranosylimidazole-4-carboxamide, } \\
\text { Mycophenolate mofetil }\end{array}$ & HEV replication inhibitor & $\begin{array}{l}\text { Inhibits inosine monophosphate } \\
\text { dehydrogenase }\end{array}$ & 51 \\
\hline Brequinar, Leflunomide & HEV replication inhibitor & $\begin{array}{l}\text { Inhibits dihydroorotate } \\
\text { dehydrogenase }\end{array}$ & 52 \\
\hline 6-azauracil & HEV replication inhibitor & $\begin{array}{l}\text { Inhibits orotidine- } 5^{\prime}- \\
\text { monophosphate decarboxylase }\end{array}$ & 52 \\
\hline 2'-C-methylcytidine & HEV replication inhibitor & Nucleoside analogue & 53 \\
\hline PPMO HP1 & HEV replication inhibitor & Inhibition of viral translation & 57 \\
\hline $\begin{array}{l}\text { 1-(9-ethylcarbazol-3-yl)-3- } \\
\text { (2-methyl-4-nitrophenyl)urea }\end{array}$ & HEV replication inhibitor & Unknown & 58 \\
\hline Zinc & HEV replication inhibitor & Unknown & 62 \\
\hline
\end{tabular}

Abbreviations: HEV, hepatitis E virus; PPMO, peptide-conjugated morpholino oligomers.

option for treating acyclovir-resistant latent herpes simplex virus infections. ${ }^{81}$

\section{Release of the progeny virions}

Release of the progeny virions from infected cells leads to the infection of neighboring uninfected cells, thus amplifying the unwanted consequences. Antivirals that prevent the release of the progeny virus will prevent further infection, thereby minimizing progression of the disease. Release of the newly assembled virus from an infected cell is a complicated process involving multiple protein-protein interactions between the virus and host factors. ${ }^{82} \mathrm{~A}$ thorough understanding of such interactions will help in decoding the mechanism underlying virus release. An inhibitor of human immunodeficiency virus release has been identified, which acts by blocking the interaction between the viral gag and host tumor susceptibility gene 101encoded proteins. ${ }^{83}$ Interaction between HEV ORF3 and host tumor susceptibility gene 101 -encoded protein is also known to mediate the release of genotype $3 \mathrm{HEV}^{84,85}$ An inhibitor against the above interaction may prove to be a potent antiviral against HEV. Apart from that, detailed investigation of HEV release mechanism should identify additional targets for antiviral development.

\section{Conclusions}

The advantages of using antivirals, particularly to cut off the disease in an infected person and providing treatment to poor responders to vaccines, such as immune-compromised patients, warrants the need for development of specific drugs against HEV. The antivirals will also prove to be useful for patients with acute, chronic or fulminant HEV infections. As summarized in Table 1 and Fig. 1, a number of promising antiviral candidates have been identified through the efforts of several researchers, which should be further characterized to identify one or more potent inhibitor(s) of HEV. A combinatorial therapy targeting crucial virus-encoded factors at different stages of viral life cycle as well as inhibition of virus-host interactions should be a potent antiviral strategy against HEV.

The recent finding of HEV inhibitory activity of zinc also appears to be an attractive area for further investigation. Zinc directly inhibits HEV RNA-dependent RNA polymerase activity in vitro and displays moderate cooperativity with ribavirin in inhibiting viral replication in mammalian cell culture models of HEV infection. Therefore, even a moderate increase in the level of bioavailable zinc may significantly improve the therapeutic benefits when combined with ribavirin therapy.

In summary, recent studies have identified multiple leads, which should be pursued further to develop a potent antiviral against HEV.

\section{Acknowledgements}

The DBT-RGYI grant and Ramalingswamy fellowship to MS is gratefully acknowledged. SA and NK are supported by senior research fellowships from the Department of Science \& Technology and the University Grants Commission, Government of India, respectively.

\section{Conflict of interest}

The authors have no conflict of interests related to this publication.

\section{Author contributions}

Wrote all sections of the manuscript except the zinc section, and generated the figure and the table (SA), wrote the zinc section of the manuscript (NK), edited the manuscript (MS). All authors read and approved the manuscript. 


\section{References}

[1] Holla RP, Ahmad I, Ahmad Z, Jameel S. Molecular virology of hepatitis E virus. Semin Liver Dis 2013;33:3-14. doi: 10.1055/s-0033-1338110.

[2] Kimura Y, Gotoh A, Katagiri S, Hoshi Y, Uchida S, Yamasaki A, et al. Transfusiontransmitted hepatitis $E$ in a patient with myelodysplastic syndromes. Blood Transfus 2014;12:103-106. doi: 10.2450/2013.0081-13.

[3] Matsubayashi K, Kang JH, Sakata H, Takahashi K, Shindo M, Kato M, et al. A case of transfusion-transmitted hepatitis $E$ caused by blood from a donor infected with hepatitis $E$ virus via zoonotic food-borne route. Transfusion 2008;48:1368-1375. doi: 10.1111/j.1537-2995.2008.01722.x.

[4] Krain LJ, Atwell JE, Nelson KE, Labrique AB. Fetal and neonatal health consequences of vertically transmitted hepatitis $E$ virus infection. Am J Trop Med Hyg 2014;90:365-370. doi: 10.4269/ajtmh.13-0265.

[5] Kumar RM, Uduman S, Rana S, Kochiyil JK, Usmani A, Thomas L. Seroprevalence and mother-to-infant transmission of hepatitis $E$ virus among pregnant women in the United Arab Emirates. Eur J Obstet Gynecol Reprod Biol 2001;100:9-15. doi: 10.1016/S0301-2115(01)00448-1

[6] Kumar A, Beniwal M, Kar P, Sharma JB, Murthy NS. Hepatitis E in pregnancy. Int J Gynaecol Obstet 2004;85:240-244. doi: 10.1016/j.ijgo.2003.11.018.

[7] Khuroo MS, Kamili S, Khuroo MS. Clinical course and duration of viremia in vertically transmitted hepatitis E virus (HEV) infection in babies born to HEVinfected mothers. J Viral Hepat 2009;16:519-523. doi: 10.1111/j.1365-2893. 2009.01101.x.

[8] Meng XJ. Expanding host range and cross-species infection of hepatitis $E$ virus. PLoS Pathog 2016;12:e1005695. doi: 10.1371/journal.ppat.1005695.

[9] Kamar N, Selves J, Mansuy JM, Ouezzani L, Péron JM, Guitard J, et al. Hepatitis E virus and chronic hepatitis in organ-transplant recipients. N Engl J Med 2008; 358:811-817. doi: 10.1056/NEJMoa0706992.

[10] Mengel AM, Stenzel W, Meisel A, Büning C. Hepatitis E-induced severe myositis. Muscle Nerve 2016;53:317-320. doi: 10.1002/mus.24959.

[11] Crum-Cianflone NF, Curry ], Drobeniuc J, Weintrob A, Landrum M, Ganesan A, et al. Hepatitis E virus infection in HIV-infected persons. Emerg Infect Dis 2012;18:502-506. doi: 10.3201/eid1803.111278.

[12] Pischke S, Suneetha PV, Baechlein C, Barg-Hock H, Heim A, Kamar N, et al. Hepatitis $\mathrm{E}$ virus infection as a cause of graft hepatitis in liver transplant recipients. Liver Transpl 2010;16:74-82. doi: 10.1002/It.21958.

[13] Pischke S, Stiefel P, Franz B, Bremer B, Suneetha PV, Heim A, et al. Chronic hepatitis e in heart transplant recipients. Am J Transplant 2012;12:3128-3133. doi: 10.1111/j.1600-6143.2012.04200.x.

[14] Miyoshi M, Kakinuma S, Tanabe Y, Ishii K, Li TC, Wakita T, et al. Chronic hepatitis $E$ infection in a persistently immunosuppressed patient unable to be eliminated after ribavirin therapy. Intern Med 2016;55:2811-2817. doi: 10.2169/internalmedicine.55.7025.

[15] Khuroo MS, Teli MR, Skidmore S, Sofi MA, Khuroo MI. Incidence and severity of viral hepatitis in pregnancy. Am J Med 1981;70:252-255. doi: 10.1016/00029343(81)90758-0

[16] Singh S, Mohanty A, Joshi YK, Dwivedi SN, Deka D. Outcome of hepatitis E virus infection in Indian pregnant women admitted to a tertiary care hospital. Indian J Med Res 2001:113:35-39.

[17] Pischke S, Behrendt P, Manns MP, Wedemeyer H. HEV-associated cryoglobulinaemia and extrahepatic manifestations of hepatitis E. Lancet Infect Dis 2014;14:678-679. doi: 10.1016/S1473-3099(14)70823-0.

[18] Dalton HR, van Eijk JJנ, Cintas P, Madden RG, Jones C, Webb GW, et al. Hepatitis $E$ virus infection and acute non-traumatic neurological injury: A prospective multicentre study. J Hepatol 2017;67:925-932. doi: 10.1016/j.jhep. 2017.07.010.

[19] Al-Shukri I, Davidson E, Tan A, Smith DB, Wellington L, Johannessen I, et al. Rash and arthralgia caused by hepatitis E. Lancet 2013;382:1856. doi: 10 . 1016/S0140-6736(13)62074-7.

[20] Drave SA, Debing Y, Walter S, Todt D, Engelmann M, Friesland M, et al. Extrahepatic replication and infection of hepatitis $E$ virus in neuronal-derived cells. J Viral Hepat 2016;23:512-521. doi: 10.1111/jvh.12515.

[21] Rein DB, Stevens GA, Theaker J, Wittenborn JS, Wiersma ST. The global burden of hepatitis E virus genotypes 1 and 2 in 2005. Hepatology 2012; 55:988-997. doi: 10.1002/hep.25505.

[22] Negi SS, Barde PV, Pathak R, Gaikwad U, Das P, Bhargav A. An outbreak of hepatitis E virus in Raipur, Chhattisgarh, India in 2014: A conventional and genetic analysis. J Med Microb Diagn 2015;4:209. doi: 10.4172/2161-0703. 1000209

[23] Chauhan NT, Prajapati P, Trivedi AV, Bhagyalaxmi A. Epidemic investigation of the jaundice outbreak in girdharnagar, ahmedabad, gujarat, India, 2008. Indian J Community Med 2010;35:294-297. doi: 10.4103/0970-0218.66864.

[24] Vivek R, Nihal L, Illiayaraja J, Reddy PK, Sarkar R, Eapen CE, et al. Investigation of an epidemic of Hepatitis $E$ in Nellore in south India. Trop Med Int Health 2010;15:1333-1339. doi: 10.1111/j.1365-3156.2010.02624.x.

[25] Tambe MP, Patil SP, Dravid M, Bhagwat VR. Investigation of an outbreak of hepatitis ' $E$ ' in a rural area of Dhule district in Maharashtra. JKIMSU 2015;4: 109-114.
[26] Kim JH, Nelson KE, Panzner U, Kasture $Y$, Labrique AB, Wierzba TF. A systematic review of the epidemiology of hepatitis E virus in Africa. BMC Infect Dis 2014;14:308. doi: 10.1186/1471-2334-14-308.

[27] Yapa CM, Furlong C, Rosewell A, Ward KA, Adamson S, Shadbolt C, et al. First reported outbreak of locally acquired hepatitis $E$ virus infection in Australia. Med J Aust 2016;204:274.

[28] Kamar N, Garrouste C, Haagsma EB, Garrigue V, Pischke S, Chauvet C, et al. Factors associated with chronic hepatitis in patients with hepatitis $\mathrm{E}$ virus infection who have received solid organ transplants. Gastroenterology 2011;140:1481-1489. doi: 10.1053/j.gastro.2011.02.050.

[29] Kamar N, Rostaing L, Abravanel F, Garrouste C, Lhomme S, Esposito L, et al. Ribavirin therapy inhibits viral replication on patients with chronic hepatitis e virus infection. Gastroenterology 2010;139:1612-1618. doi: 10.1053/j.gastro. 2010.08.002.

[30] Mallet V, Nicand E, Sultanik P, Chakvetadze C, Tessé S, Thervet E, et al. Brief communication: case reports of ribavirin treatment for chronic hepatitis $\mathrm{E}$. Ann Intern Med 2010;153:85-89. doi: 10.7326/0003-4819-153-2201007200-00257.

[31] Pischke S, Hardtke S, Bode U, Birkner S, Chatzikyrkou C, Kauffmann W, et al. Ribavirin treatment of acute and chronic hepatitis $\mathrm{E}$ : a single-centre experience. Liver Int 2013;33:722-726. doi: 10.1111/liv.12114.

[32] Gerolami R, Borentain P, Raissouni F, Motte A, Solas C, Colson P. Treatment of severe acute hepatitis E by ribavirin. J Clin Virol 2011;52:60-62. doi: 10 . 1016/j.jcv.2011.06.004.

[33] Debing Y, Emerson SU, Wang Y, Pan Q, Balzarini J, Dallmeier K, et al. Ribavirin inhibits in vitro hepatitis $E$ virus replication through depletion of cellular GTP pools and is moderately synergistic with alpha interferon. Antimicrob Agents Chemother 2014;58:267-273. doi: 10.1128/AAC.01795-13.

[34] Debing Y, Gisa A, Dallmeier K, Pischke S, Bremer B, Manns M, et al. A mutation in the hepatitis E virus RNA polymerase promotes its replication and associates with ribavirin treatment failure in organ transplant recipients. Gastroenterology 2014;147:1008-1011.e7. doi: 10.1053/j.gastro.2014.08.040.

[35] Lhomme S, Kamar N, Nicot F, Ducos J, Bismuth M, Garrigue V, et al. Mutation in the hepatitis $E$ virus polymerase and outcome of ribavirin therapy. Antimicrob Agents Chemother 2015;60:1608-1614. doi: 10.1128/AAC.02496-15.

[36] Todt D, Gisa A, Radonic A, Nitsche A, Behrendt P, Suneetha PV, et al. In vivo evidence for ribavirin-induced mutagenesis of the hepatitis $E$ virus genome. Gut 2016;65:1733-1743. doi: 10.1136/gutjnl-2015-311000.

[37] Todt D, Walter S, Brown RJ, Steinmann E. Mutagenic effects of ribavirin on hepatitis $E$ virus-viral extinction versus selection of fitness-enhancing mutations. Viruses 2016;8:283. doi: 10.3390/v8100283.

[38] Pradat P, Virlogeux V, Gagnieu MC, Zoulim F, Bailly F. Ribavirin at the era of novel direct antiviral agents for the treatment of hepatitis $C$ virus infection: relevance of pharmacological monitoring. Adv Hepatol 2014;2014:493087. doi: $10.1155 / 2014 / 493087$.

[39] Kamar N, Abravanel F, Garrouste C, Cardeau-Desangles I, Mansuy JM, Weclawiak $\mathrm{H}$, et al. Three-month pegylated interferon-alpha-2a therapy for chronic hepatitis E virus infection in a haemodialysis patient. Nephrol Dial Transplant 2010;25:2792-2795. doi: 10.1093/ndt/gfq282.

[40] Dalton H, Bendall R, Keane F, Neale R, Tedder R, Ijaz S. P61 Pegylated interferon and ribavarin combination therapy achieves hepatitis $E$ virus clearance in chronic hepatitis $E$ virus/human immunodeficiency virus co-infection. Gut 2010;59:A35-A36. doi: 10.1136/gut.2010.223362.87.

[41] Haagsma EB, Riezebos-Brilman A, van den Berg AP, Porte RJ, Niesters HG. Treatment of chronic hepatitis $E$ in liver transplant recipients with pegylated interferon alpha-2b. Liver Transpl 2010;16:474-477. doi: 10.1002/It.22014.

[42] Alric L, Bonnet D, Laurent G, Kamar N, Izopet J. Chronic hepatitis E virus infection: successful virologic response to pegylated interferon-alpha therapy. Ann Intern Med 2010;153:135-136. doi: 10.7326/0003-4819-153-2201007200-00256.

[43] Todt D, François $C$, Anggakusuma, Behrendt $P$, Engelmann $M$, Knegendorf $L$, et al. Antiviral activities of different interferon types and subtypes against hepatitis E virus replication. Antimicrob Agents Chemother 2016;60: 2132-2139. doi: 10.1128/AAC.02427-15.

[44] Zhou X, Xu L, Wang W, Watashi K, Wang Y, Sprengers D, et al. Disparity of basal and therapeutically activated interferon signalling in constraining hepatitis E virus infection. J Viral Hepat 2016;23:294-304. doi: 10.1111/jvh.12491.

[45] Nan Y, Yu Y, Ma Z, Khattar SK, Fredericksen B, Zhang YJ. Hepatitis E virus inhibits type I interferon induction by ORF1 products. J Virol 2014;88: 11924-11932. doi: 10.1128/JVI.01935-14.

[46] Dong C, Zafrullah M, Mixson-Hayden T, Dai X, Liang J, Meng J, et al. Suppression of interferon- $\alpha$ signaling by hepatitis $E$ virus. Hepatology 2012;55:1324-1332. doi: 10.1002/hep.25530.

[47] Chandra V, Kar-Roy A, Kumari S, Mayor S, Jameel S. The hepatitis E virus ORF3 protein modulates epidermal growth factor receptor trafficking, STAT3 translocation, and the acute-phase response. J Virol 2008;82:7100-7110. doi: 10.1128/JVI.00403-08.

[48] Raison CL, Demetrashvili M, Capuron L, Miller AH. Neuropsychiatric adverse effects of interferon-alpha: recognition and management. CNS Drugs 2005; 19:105-123. doi: 10.2165/00023210-200519020-00002 
[49] Kamar N, Rostaing L, Abravanel F, Garrouste C, Esposito L, Cardeau-Desangles I, et al. Pegylated interferon-alpha for treating chronic hepatitis $E$ virus infection after liver transplantation. Clin Infect Dis 2010;50:e30-e33. doi: 10.1086/ 650488.

[50] Debing $Y$, Neyts J. Antiviral strategies for hepatitis E virus. Antiviral Res 2014;102:106-118. doi: 10.1016/j.antiviral.2013.12.005.

[51] Wang Y, Zhou X, Debing Y, Chen K, Van Der Laan L], Neyts J, et al. Calcineurin inhibitors stimulate and mycophenolic acid inhibits replication of hepatitis $\mathrm{E}$ virus. Gastroenterology 2014;146:1775-1783. doi: 10.1053/j.gastro.2014. 02.036.

[52] Wang Y, Wang W, Xu L, Zhou X, Shokrollahi E, Felczak K, et al. Cross talk between nucleotide synthesis pathways with cellular immunity in constraining hepatitis E virus replication. Antimicrob Agents Chemother 2016;60: 2834-2848. doi: 10.1128/AAC.02700-15.

[53] Qu C, Xu L, Yin Y, Peppelenbosch MP, Pan Q, Wang W. Nucleoside analogue 2'C-methylcytidine inhibits hepatitis $\mathrm{E}$ virus replication but antagonizes ribavirin. Arch Virol 2017;162:2989-2996. doi: 10.1007/s00705-017-3444-8.

[54] Dao Thi VL, Debing Y, Wu X, Rice CM, Neyts J, Moradpour D, et al. Sofosbuvir inhibits hepatitis $E$ virus replication in vitro and results in an additive effect when combined with ribavirin. Gastroenterology 2016;150:82-85.e4. doi: 10.1053/j.gastro.2015.09.011.

[55] Wang W, Hakim MS, Nair VP, de Ruiter PE, Huang F, Sprengers D, et al. Distinct antiviral potency of sofosbuvir against hepatitis $\mathrm{C}$ and $\mathrm{E}$ viruses. Gastroenterology 2016;151:1251-1253. doi: 10.1053/j.gastro.2016.09.061.

[56] Donnelly MC, Imlach SN, Abravanel F, Ramalingam S, Johannessen I, Petrik J, et al. Sofosbuvir and daclatasvir anti-viral therapy fails to clear HEV viremia and restore reactive t cells in a $\mathrm{HEV} / \mathrm{HCV}$ co-infected liver transplant recipient. Gastroenterology 2017;152:300-301. doi: 10.1053/j.gastro.2016.05.060.

[57] Nan Y, Ma Z, Kannan H, Stein DA, Iversen PI, Meng XJ, et al. Inhibition of hepatitis $\mathrm{E}$ virus replication by peptide-conjugated morpholino oligomers. Antiviral Res 2015;120:134-139. doi: 10.1016/j.antiviral.2015.06.006.

[58] Madhvi A, Hingane S, Srivastav R, Joshi N, Subramani C, Muthumohan R, etal. A screen for novel hepatitis $C$ virus RdRp inhibitor identifies a broad-spectrum antiviral compound. Sci Rep 2017;7:5816. doi: 10.1038/s41598-017-04449-3.

[59] Kisselev AF, van der Linden WA, Overkleeft HS. Proteasome inhibitors: an expanding army attacking a unique target. Chem Biol 2012;19:99-115. doi: 10.1016/j.chembiol.2012.01.003.

[60] Karpe YA, Meng X]. Hepatitis E virus replication requires an active ubiquitinproteasome system. J Virol 2012;86:5948-5952. doi: 10.1128/JVI.07039-11.

[61] Xu L, Zhou X, Peppelenbosch MP, Pan Q. Inhibition of hepatitis E virus replication by proteasome inhibitor is nonspecific. Arch Virol 2015;160:435-439. doi: 10.1007/s00705-014-2303-0.

[62] Kaushik N, Subramani C, Anang S, Muthumohan R, Shalimar, Nayak B, et al. Zinc salts block hepatitis $E$ virus replication by inhibiting the activity of viral RNA-dependent RNA polymerase. J Virol 2017;91:e00754-17. doi: 10. 1128/JVI.00754-17.

[63] Prasad AS. Zinc: an overview. Nutrition 1995;11:93-99.

[64] John E, Laskow TC, Buchser WJ, Pitt BR, Basse PH, Butterfield LH, et al. Zinc in innate and adaptive tumor immunity. J Transl Med 2010;8:118. doi: 10. 1186/1479-5876-8-118.

[65] Grüngreiff $K$, Reinhold D. Zinc: A complementary factor in the treatment of chronic hepatitis C? (Review). Mol Med Rep 2010;3:371-375. doi: 10. 3892/mmr_00000267.

[66] Kalia M, Chandra V, Rahman SA, Sehgal D, Jameel S. Heparan sulfate proteoglycans are required for cellular binding of the hepatitis $E$ virus ORF2 capsid protein and for viral infection. J Virol 2009;83:12714-12724. doi: 10.1128/JVI.00717-09.

[67] Zheng ZZ, Miao J, Zhao M, Tang M, Yeo AE, Yu H, et al. Role of heat-shock protein 90 in hepatitis E virus capsid trafficking. J Gen Virol 2010;91: 1728-1736. doi: 10.1099/vir.0.019323-0.
[68] Yu H, Li S, Yang C, Wei M, Song C, Zheng Z, et al. Homology model and potential virus-capsid binding site of a putative HEV receptor Grp78. J Mol Model 2011;17:987-995. doi: 10.1007/s00894-010-0794-5.

[69] Nain M, Mukherjee S, Karmakar SP, Paton AW, Paton JC, Abdin MZ, et al. GRP78 is an important host factor for japanese encephalitis virus entry and replication in mammalian cells. J Virol 2017;91:e02274-16. doi: 10.1128/ JVI.02274-16.

[70] Magden J, Takeda N, Li T, Auvinen P, Ahola T, Miyamura T, et al. Virus-specific mRNA capping enzyme encoded by hepatitis E virus. J Virol 2001;75: 6249-6255. doi: 10.1128/JVI.75.14.6249-6255.2001.

[71] Decroly E, Ferron F, Lescar J, Canard B. Conventional and unconventional mechanisms for capping viral mRNA. Nat Rev Microbiol 2011;10:51-65. doi: $10.1038 /$ nrmicro2675.

[72] Emerson SU, Nguyen H, Graff J, Stephany DA, Brockington A, Purcell RH. In vitro replication of hepatitis $E$ virus (HEV) genomes and of an HEV replicon expressing green fluorescent protein. J Virol 2004;78:4838-4846. doi: 10. 1128/JVI.78.9.4838-4846.2004

[73] Woyciniuk $P$, Linder $M$, Scholtissek $C$. The methyltransferase inhibitor Neplanocin A interferes with influenza virus replication by a mechanism different from that of 3-deazaadenosine. Virus Res 1995;35:91-99. doi: 10.1016/01681702(94)00085-Q

[74] Borchardt RT, Keller BT, Patel-Thombre U. Neplanocin A. A potent inhibitor of $\mathrm{S}$-adenosylhomocysteine hydrolase and of vaccinia virus multiplication in mouse L929 cells. J Biol Chem 1984;259:4353-4358.

[75] Barral K, Sallamand C, Petzold C, Coutard B, Collet A, Thillier Y, et al. Development of specific dengue virus 2'-O- and N7-methyltransferase assays for antiviral drug screening. Antiviral Res 2013;99:292-300. doi: 10.1016/j.antiviral. 2013.06.001.

[76] Pawlotsky JM. NS5A inhibitors in the treatment of hepatitis C. J Hepatol 2013;59:375-382. doi: 10.1016/j.jhep.2013.03.030

[77] Nair VP, Anang S, Subramani C, Madhvi A, Bakshi K, Srivastava A, et al. Endoplasmic reticulum stress induced synthesis of a novel viral factor mediates efficient replication of genotype-1 hepatitis E virus. PLoS Pathog 2016; 12: e1005521. doi: 10.1371/journal.ppat.1005521.

[78] Subramani C, Nair VP, Anang S, Mandal SD, Pareek M, Kaushik N, et al. Hostvirus protein interaction network reveals the involvement of multiple host processes in the life cycle of hepatitis E virus. mSystems 2018;3:e00135-17. doi: 10.1128/mSystems.00135-17.

[79] Karpe YA, Lole KS. RNA 5'-triphosphatase activity of the hepatitis E virus helicase domain. J Virol 2010;84:9637-9641. doi: 10.1128/JVI.00492-10.

[80] Frick DN, Lam AM. Understanding helicases as a means of virus control. Curr Pharm Des 2006;12:1315-1338. doi: 10.2174/138161206776361147

[81] Crute J], Grygon CA, Hargrave KD, Simoneau B, Faucher AM, Bolger G, et al. Herpes simplex virus helicase-primase inhibitors are active in animal models of human disease. Nat Med 2002;8:386-391. doi: 10.1038/nm0402-386.

[82] Ravindran MS, Bagchi P, Cunningham CN, Tsai B. Opportunistic intruders: how viruses orchestrate ER functions to infect cells. Nat Rev Microbiol 2016;14:407-420. doi: 10.1038/nrmicro.2016.60.

[83] Tavassoli A, Lu Q, Gam J, Pan H, Benkovic SJ, Cohen SN. Inhibition of HIV budding by a genetically selected cyclic peptide targeting the Gag-TSG101 interaction. ACS Chem Biol 2008;3:757-764. doi: 10.1021/cb800193n.

[84] Surjit M, Oberoi R, Kumar R, Lal SK. Enhanced alpha1 microglobulin secretion from Hepatitis E virus ORF3-expressing human hepatoma cells is mediated by the tumor susceptibility gene 101. J Biol Chem 2006;281: 8135-8142. doi: 10.1074/jbc.M509568200.

[85] Nagashima S, Takahashi M, Jirintai, Tanaka T, Yamada K, Nishizawa T, et al. A PSAP motif in the ORF3 protein of hepatitis $E$ virus is necessary for virion release from infected cells. J Gen Virol 2011;92:269-278. doi: 10.1099/vir. 0.025791-0. 